\title{
Conceptualizing Thriving: An Exploration of Students' Perceptions of Positive Functioning Within Graduate Education
}

\author{
Heather A. Coe-Nesbitt ${ }^{1}$, Eleftherios K. Soleas ${ }^{1,2 *}$, Anoushka M. Moucessian ${ }^{3}$, \\ Nadia Arghash ${ }^{1}$ and Benjamin Kutsyuruba ${ }^{1}$ \\ ${ }^{1}$ Faculty of Education, Queen's University, Kingston, ON, Canada, ${ }^{2}$ Office of Professional Development and Educational \\ Scholarship, Faculty of Health Sciences, Queen's University, Kingston, ON, Canada, ${ }^{3}$ School of Kinesiology and Health Studies, \\ Queen's University, Kingston, ON, Canada
}

OPEN ACCESS

Edited by:

Royel Johnson,

The Pennsylvania State University (PSU), United States

Reviewed by:

Meghan Pifer.

University of Louisville, United States

Steven Jefferson,

Rice University, United States

${ }^{*}$ Correspondence:

Eleftherios $K$. Soleas

eks3@queensu.ca

Specialty section: This article was submitted to Higher Education,

a section of the journa

Frontiers in Education

Received: 01 May 2021 Accepted: 06 July 2021

Published: 21 July 2021

Citation:

Coe-Nesbitt HA, Soleas EK, Moucessian AM, Arghash N and Kutsyuruba B (2021) Conceptualizing Thriving: An Exploration of Students' Perceptions of Positive Functioning

Within Graduate Education.

Front. Educ. 6:704135.

doi: 10.3389/feduc.2021.704135
The current wellness crisis among graduate students calls on institutions of higher education to act and advocate for student thriving. While existing research on human thriving provides insight into how this experience of positive functioning can be understood across the lifespan, what it means to thrive within graduate programs - and by extension, how to support students in their ability to thrive within these programs-remains understudied. To address this gap in the literature, this study examined how graduate students describe and understand thriving within their programs of study. We thematically and quantitatively analyzed 2,287 Canadian graduate students survey responses to the question "How would you describe a student who is thriving in your program." Findings indicate that graduate students conceptualize thriving as a complex and multi-dimensional construct involving both academic and non-academic components. The six overarching themes of achieving, engaging, connecting, balancing, enjoying, and being provide foundation for further exploration and insight into the ways that universities and postsecondary institutions can support students' positive functioning.

Keywords: thriving, well-being, graduate student, graduate programs, higher education, positive functioning

\section{INTRODUCTION}

Graduate programs aim to foster the development of the next generation of researchers, scholars, professionals, and leaders within a multitude of fields. The masters and doctoral students (graduate students) nurtured within these programs are future thinkers, leaders, researchers, and scholars who create policy, opportunities, and solutions for humanity through study, contemplation, and knowledge creation [Canadian Association for Graduate Studies (Canadian Association for Graduate Studies [CAGS], 2012)]. These students' well-being are worthy of investigation as it makes their ability to contribute to a brighter future for humanity more likely. However, while on the path toward an idealized future, graduate students face unique challenges and stressors, such as those emerging from financial burdens, supervisory relationships, and scholastic pressure (e.g., publish or perish, tenure or you have settled), that can have a negative impact on student retention (Declou, 2016; Kim, 2011) and overall well-being (Evans et al., 2018). Indeed, graduate students have been found to have such high levels of distress, anxiety, depression, and other mental health issues that it has been described as a mental health crisis and efforts to investigate and support the creation of 
thriving-supportive learning environments has been labelled a necessity (Charles et al., 2021; Posselt, 2021). As graduate programs continue to experience tremendous growth (Association of Universities and Colleges of Canada, 2011; Okahana and Zhou, 2017; Universities Canada, 2020), the need to address systemic pressures that can impact student well-being and support students in their ability to thrive within their programs of study becomes ever more important.

\section{Graduate Student Experience: A Brief Review of Literature}

In Canada, graduate education typically includes two types of programs: 1) Masters programs that are frequently one-to twoyears in length full-time, which follow an undergraduate degree; and 2) Doctoral or $\mathrm{PhD}$ programs that are frequently completed in four to six years full-time following a Masters degree. The experience of graduate students is fundamentally different to that of their undergraduate peers and, thus, requires unique attention and support from higher education leaders, stakeholders, and researchers (Canadian Association for Graduate Studies [Canadian Association for Graduate Studies [CAGS], 2012). Graduate students frequently operate within less structured environments, when compared to undergraduate students who may study within tightly defined course schedules, that require self-motivation and self-directed independent study far in excess of undergraduate programs (Peters, 1997; Owens et al., 2020). In addition, most graduate programs require students to work alongside a supervisor, whose supportiveness (or lack thereof) has been shown to be a predictor of graduate student satisfaction (Dericks et al., 2019; Blanchard \& Haccoun, 2020). In addition to their academic responsibilities, graduate students are more likely than undergraduate students to have familial and professional obligations (Hyun et al., 2006; Alena and Cliff, 2018), a challenge that has been shown to reduce the likelihood of program completion (Declou, 2016). It has also been noted that despite graduate students constituting a significant proportion of students on university campuses, the bulk of resources are typically allocated to facilitating belonging among primarily undergraduate students (Pascale, 2018). As understandable as this prioritization of resources for the larger group might be, this approach still leaves graduate students isolated and undersupported. Even as the number of individuals enrolled in graduate programs continues to increase over time (Association of Universities and Colleges of Canada, 2011; Okahana and Zhou, 2017), alumni face a changing and unpredictable academic labour market with declining job security upon graduation (Acker and Haque, 2017; McAlpine and Austin, 2019).

For some, the graduate student experience is a time-intensive struggle of balancing work, life, and the demands of multiple roles (Blanchard and Haccoun, 2020; Lorusso et al., 2020). Students' perceived ability to balance academic and non-academic undertakings can have an impact on their self-efficacy (Yusuf et al., 2020) and resourcefulness (Reed and Kennett, 2017), as well as their mental health (Sprung and Rogers, 2020). Relatedly, access to adequate funding has been shown to impact program completion and students' ability to engage in important academic tasks, such as publishing (Larivière, 2013). Financial instability, anxiety associated with time to completion, workload, access to career development opportunities, campus culture, and availability and access to support mechanisms have all been found to impact the graduate student experience (Rummell, 2015; Declou, 2016; Giamos et al., 2017; McAlpine and Austin, 2019; Ahn and Davis, 2020). Moreover, students encounter these various stressors in tandem with the mandatory requirements of rigorous academic programs (Breen, 2019; Canadian Association for Graduate Studies, 2006; e.g., comprehensive examinations, thesis defense), while also functioning within a higher education environment that calls for high student productivity (Saliba and Slater, 2012).

Given the myriad of challenges that graduate students encounter as they complete the academic obligations associated with degree completion, supporting student wellbeing should be front of mind for those working within graduate programs and post-secondary institutions. The current "mental health crisis in graduate education" (Evans et al., 2018, p. 282) calls on leaders to act and advocate for student thriving, with the understanding that attending to student well-being is a fundamental purpose of higher education (Evans et al., 2018; Soleas et al., 2019). However, supporting graduate students in their ability to thrive requires an understanding of what such an experience entails within the contexts of higher education and graduate programs, more specifically.

\section{Graduate Student Thriving: A Conceptual Framework}

Human thriving can be understood as a desirable life condition (Bundick et al., 2010): "When people are thriving, they feel progress and momentum, marked by a sense of learning (greater understanding and knowledge) and a sense of vitality (aliveness)" (Spreitzer et al., 2005, p. 537). While existing research provides insight into how human thriving can be conceptualized and understood across the lifespan (e.g., Benson and Scales, 2009; Bundick et al., 2010; Weiss and Burnham Riosa, 2015; Nesbitt, 2019) and within the workplace (e.g., Spreitzer et al., 2005; Hoffman et al., 2007; Grayson and Alvarez, 2008; Jennings and Greenberg, 2009; Koenig, 2014; Cullen et al., 2018), thriving within post-secondary institutions, until recently, has been largely overlooked. Over the past decade, research has begun to shed light on student thriving within the undergraduate context (e.g., Berea et al., 2015; Schreiner, 2010, Schreiner, 2013). Of particular note is the work conducted by Schreiner (2010) and colleagues, who describe a thriving student as one who is "fully engaged intellectually, socially, and emotionally" (p. 4) and argue that thriving in College is about more than merely surviving. Schreiner (2010) advocates that a focus on thriving moves away from "failure prevention to success promotion" ( $\mathrm{p}$. 10) among students.

A focus on thriving builds on an understanding gained through engagement measures, activity, and other focusrelated measures (e.g., attention, attendance, presence) and does so by providing a holistic view that is wide-enough to see 
a range of opportunities and issues that can influence the overall wellness and lives of graduate students. Even with Schreiner (2013) groundbreaking work, student thriving among graduate students remains understudied and little is known about the factors associated with their sense of fulfillment within their academic experiences such as work-life balance, quality of life, and achievement of their goals (Yusuf et al., 2020). The current study aimed to directly address this gap by examining how graduate students describe and understand student thriving within their post-secondary graduate programs of study. To achieve this purpose, we sought the perspectives of graduate students to develop a contextually appropriate conceptualization of graduate student thriving. This research was guided by one key question: How do graduate students at one mid-sized Canadian university conceptualize thriving within their graduate studies? Findings from this study provide unique insight into student thriving and the graduate student experience. Subsequently, we propose a contextually appropriate and data-driven definition of graduate student thriving to inform future work in this important area.

\section{METHODOLOGY}

This research is part of a larger study utilizing a two-phase convergent mixed-methods methodology (Johnson and Onwuegbuzie, 2004; Mertens, 2014) to explore student thriving and well-being among graduate and professional students. The approach to data collection combines two identical phases in the fall and spring terms consisting of open- and closed-items drawn and adapted from literature on a survey administered twice a year over three years. The survey was designed to include common and emergent demographic items from the above reviewer higher-education literature as well as constructs from the motivation literature. The current study focuses on graduate students' (those completing masters and doctoral degrees) open-ended responses $(\mathrm{N}=2,287)$ and demographic questions collected over a three-year period. Findings were drawn from thematic analysis and subsequent quantitization of these patterns for non-parametric statistics.

\section{Data Collection}

After obtaining university research ethics clearance, we sought and received endorsement from the university graduate and professional student society to aid in survey dissemination. Surveys were distributed via email in the fall and spring term of the 2016-2017 (Year 1), 2017-2018 (Year 2), and 2018-2019 (Year 3) school years. Recruited participants completed online questionnaires consisting of demographic questions, quantitative items, and open-ended questions. The current study examines data provided by graduate students in response to one openended essay-style item (How would you describe a student who is thriving in your program?) and related demographic data. Previous literature on human thriving emphasizes the contextually-specific nature of this construct (e.g., adolescence-Benson and Scales, 2009; workplace - Spreitzer et al., 2005; College-Schreiner, 2013). Therefore, the open- ended question was designed to focus and elicit participant's contextually-grounded perceptions of student thriving in their program. By asking about and analyzing this experience with one open-ended item, students were invited to report the factors and considerations most important and present from their perspective and were not skewed to consider dimensions introduced by the research team.

In Year 1, data were collected from a total of 149 participants from two university graduate departments (Education and Kinesiology/Health studies). With support of the university graduate and professional student society, the study expanded university-wide in the subsequent years, with 1,349 participants across 39 graduate departments in Year 2 and 789 participants across 35 graduate departments in Year 3. Graduate departments spanned health sciences, business, humanities, sciences, engineering, and social sciences. In total, the final sample for the study consisted of 2,287 survey completions constituting a response rate of approximately $24 \%$ from 59 graduate programs.

\section{Data Analysis}

Data were analyzed sequentially using first qualitative and then quantitative methods to answer the research question. The common elements of student thriving (e.g., academic and holistic health) were used to organize responses initially when interpreting data and over time yielded the themes via the process described below. Open-ended responses from the identified survey question were thematically analyzed (Braun and Clarke, 2019) using a multi-stage, systematic approach that combined both inductive and deductive qualitative analysis (Patton, 2015; Creswell and Creswell, 2017). To ensure consistency of approach, at each stage of analysis, research team members met to collaboratively code (Cohen's Kappa $=0.886$, indicating very good intercoder agreement), and to discuss and consolidate preliminary findings and to construct a shared understanding of the qualitative data.

Year 1 data were thematically analyzed through open-coding, development of categories, and identification of overarching themes (Basit, 2010). At this stage of analysis, codes, categories, and themes were labelled using an inductive approach to reflect the voices of the participants (Creswell and Clark, 2017). As analysis progressed into the Year 2 and Year 3 data, codes, categories, and themes were added and adapted based on the new data (using a combination of inductive and deductive approaches with the Year 1 analysis as a coding guide). During the course of open-coding, categories and subsequent themes began to emerge as prevailing ideas that neatly housed clusters of related ideas. As analysis progressed, emergent themes became clearer and lead to a final stage of analysis with six overarching themes, consisting of 37 categories.

Qualitative analysis revealed that participants' descriptions of student thriving appeared to span across a continuum, ranging from primarily academic in focus on one end to primarily nonacademic in focus at the other. At the centre of this continuum, there appeared to be perspectives that included more balanced descriptions of student thriving that included elements that were both academic- and non-academic in nature. To make better sense of these findings, the conceptualizations of thriving 
provided by participants were subsequently quantitized for nonparametric statistics (Sandelowski and Barroso, 2003; Sandelowski et al., 2009). Participant responses to the focal question were grouped into three categories: primarily academic (e.g., my thriving is mostly driven by my academic prowess); balanced (e.g., my thriving is a balance of academic and non-academic indicators); and primarily non-academic (e.g., my thriving is mostly driven by quality of life outside of academia and beyond the context of higher education). This approach to grouping first required the consensus among the research team to identify inclusion/exclusion criteria for three categories and then consensus coding the responses into one of the three categories as a research team.

To maintain internal consistency, a consensus was established among the researchers so that: 1) if the distinct factors provided in the survey response were $70 \%$ or more clearly identified with achievements or focus in academic life (e.g., publishing, getting high grades, degree progress, securing funding, working long hours), then the definition would be coded as primarily academic; 2) if the factors provided were $70 \%$ or more to do with aspects typically situated beyond the school setting (e.g., getting enough sleep, eating well, exercising, maintaining a social life outside of the program), then the definition would be coded as primarily non-academic; and 3) if the factors provided met neither of the thresholds and articulated a balance of both academic and non-academic considerations (e.g., completing academic milestones, maintaining a work-life balance, and eating well), then the definition would be coded as a balanced conceptualization of thriving. These descriptions and conceptualizations of student thriving were then further examined using a set of Chi-Square tests. These non-parametric tests compare groups to determine if the distribution of thriving conceptualizations is different by demographic or temporal groupings. A significant result on a Chi-Square test would show that the proportion of thriving conceptualizations (dependent variable; e.g., academic, balanced, non-academic) were found to be different depending on that demographic factor (independent variable, e.g., gender, age, program of study).

\section{Findings}

A total of 2,287 graduate participants responded to the survey answering all the questions. By gender, $70.8 \%$ of participants were female, $28.2 \%$ were male, and $1 \%$ self-identified as not identifying with a gender binary. This finding reflects a slight gender skew in favour of female participants. However, the non-parametric nature of the analyses mitigated the influence that this skew could have introduced in the form of unbalanced comparison if we had used parametric statistics. Of this sample, $75.4 \%$ selfidentified as domestic students, $15.3 \%$ as out of province students, and $9.3 \%$ as international students. Master's students constituted $79.7 \%$ of the sample, with the remaining $20.3 \%$ being doctoral students. Findings illuminate a rich and multi-dimensional understanding of what it means to thrive within postsecondary graduate studies.

\section{Qualitative Findings}

Qualitative analysis of open-ended survey responses to the question, "How would you describe a student who is thriving in your program?" revealed six overarching themes: 1) Achieving; 2) Engaging; 3) Connecting; 4) Balancing; 5) Enjoying; and 6) Being. The labels for the six overarching themes capture the essence of their corresponding codes and categories, and are written as verbs to reflect the active way in which participants described these various dimensions of thriving within their graduate programs.

Qualitative findings indicate that graduate students understood thriving as a holistic, interconnected, and multidimensional construct. While participants described thriving in unique and individualized ways, many commonalities were observed across the perspectives (see Table 1). It is important to note that while six overarching themes were identified, there was much overlap and connection among the ideas presented within them.

Achieving. The theme of achieving captures progress towards and attainment of academic goals and milestones, and reflects the idea that success and progress in academic pursuits are closely tied to graduate student thriving. Accomplishments, such as meeting deadlines and making progress in one's program of study (e.g., completing comprehensive examples, attaining research ethics clearance, being on schedule for degree completion), emerged from the data as strong indicators of a thriving graduate student. Likewise, developing knowledge and having "consistent personal growth" was also viewed by participants as a sign of achieving in relation to thriving. In addition to meeting degree milestones and markers, participants illuminated the idea that a thriving graduate student is attending and presenting at conferences, getting published, and is receiving recognition for their work (e.g., "someone who is winning major awards"). For example, one participant suggested that thriving students "are truly experts in their field because of all the readings that they have done and from being active by attending events that are relevant to their field." Likewise, another participant asserted: "They have the time and the opportunity to attend conferences, work on academic publishing, and, if needed or desired, work outside of campus with the support of faculty."

In addition to obtaining good grades (e.g., "someone who does well in class;" "getting excellent grades;" "pass their exams with excellency"), participants also spoke of how thriving graduate students are likely obtaining career-related experience, such as teaching or career development training, and are well-positioned for future employment (e.g., "proactive and planning for employment opportunities upon graduation;" "job interviews or job lined up;" "skills needed to succeed in their career aspirations"). Similarly, having goals and aspirations for the future were also viewed as indicators of a thriving graduate student. For example, one participant commented: "like every other thing in life, timing, planning, and looking beyond now is very important." Another participant asserted that a thriving student will "have lots of thoughts about future research direction/analysis, know what they want to do after they graduate." 
TABLE 1 | Overview of the overarching themes and categories emerging from qualitative analysis.

\section{Overarching theme}

\section{Categories}

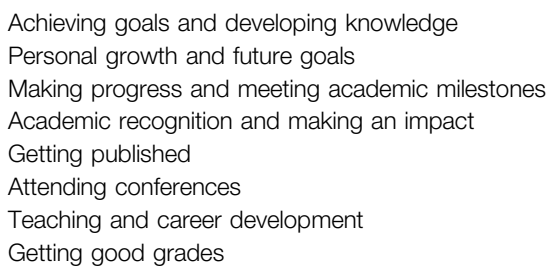

Attendance and active participation

Engaged (general)

Engaged in research

Involved in various campus projects and activities

Beyond campus involvement
Engaging. The theme of engaging embraces the notion that thriving graduate students are actively involved and absorbed in their learning, program, and various school experiences. Participants highlighted that a thriving student is someone who is physically present (e.g., "someone who shows up to the lab every day;" "is not missing meetings or events they should be attending"), attending and participating in class, seminars, lectures, and labs on a regular basis. Similarly, a thriving student was described by participants as someone who is "prepared" for class (e.g., having completed all readings) and as someone who arrives at school ready to "actively participate" and engage in class and other learning experiences, such as discussions, group activities, course work, readings, and research.

Beyond the classroom, participants highlighted that a thriving graduate student is "engaged" and "involved" in various ways at the program, department, university, and/or community level. For example, one participant suggested that a thriving student is "socially and academically engaged," while another commented that a thriving student likely is "involved in their department and community." In many survey responses, participants highlighted specific ways that thriving students are engaging, such as being involved in research (e.g., "the student is producing meaningful and scientifically accurate graduate research within a supportive environment;" "focusing on their research, not competing"), extracurricular activities (e.g., "involvement in organizations and work;" "student can participate in extra-curricular activities, [such as] student activism, community activism, etc.; " "attending departmental talks"), groups and committees (e.g., "member of an important academic committee;" "involved in graduate student committees within and outside of the department;" "participation in reading groups"), and events and experiences that reach beyond the university (e.g., "active in the community;" "attending social events;" "actively involved outside of just the academic side of the program").

Connecting. The theme of connecting highlights the importance of relationships and interpersonal interactions and supports to student thriving. In this respect, a thriving graduate student was perceived by participants as someone who is 
connected to others, to their academic community, and to a system of support. Participants indicated that a thriving graduate student likely experiences a sense of belonging within their program of study (e.g., "someone who feels full integrated into the social atmosphere of the department" and "feels comfortable in their work space and interacting with colleagues and mentors") and feels respected and valued by peers, colleagues, and within their department, university, and/or profession (e.g., "Someone who feels valued for their intrinsic worth, and their value to the department and program, the work and ideas they produce, most importantly valued in this way by themselves."). Likewise, participants described a thriving graduate student as someone who has a "strong support network," possessing "various forms of social and material support," and as someone who knows "how to use all the resources available." Moreover, being able to provide support and mentorship to others (e.g., "is open and available to mentor others;" "is a good example to look up to") was also viewed as an indicator of thriving.

Numerous participants emphasized the powerful role that interpersonal relationships play in student thriving. Although the words used to describe these critical relationships varied (including "good," "positive," "strong," "healthy," "caring," "great," and "friendly"), findings indicated that a thriving graduate student is not only connected to support systems, but also actively connecting with others and developing positive and supportive interpersonal relationships. This graduate student was perceived by participants as someone who has and is developing positive relationships with peers and faculty, including supervisors.

While friendships were identified by participants as an indicator of student thriving, the existence of a strong support network (consisting of peers, faculty, and staff) and a positive working relationship with one's supervisor (supportive, regular communication, timely feedback) were highlighted as integral. For example, one participant commented that a thriving student "is supported by their mentor/supervisor who is checking in regularly with them, ensuring they are progressing in their study/ research, understands that isolation is often an issue during this process and checks in to ensure they are doing well." Another respondent asserted that a thriving graduate student is someone who has an "inspiring supervisor and collaborative colleagues that can support their journey through their program." Further supporting the notion that supervisors play an essential role in student thriving, one participant stated: "A student who is thriving is being pushed to do their best, while not being overwhelmed by their supervisor." Articulating the idea that thriving is not a permanent state and must constantly be assessed and supported over, another participant commented that: "Having a good relationship with your direct supervisor can be really key to keeping motivation and excitement for a long project, such as a thesis." The participant continued: "Additionally, having a good support group of friends and colleagues around for both academic and moral support helps one thrive in their program."

Balancing. The theme of balancing captures the idea that a thriving graduate student can establish and maintain a balanced lifestyle. Balancing speaks to the idea that thriving involves the ability to balance the demands of a graduate program with that of paid or unpaid work and life beyond school. It also implies that a thriving student is able to manage stress and maintain holistic health (physical, mental, social, emotional, spiritual). For example, a thriving student was seen by participants as "someone who is able to meet the demands of the program of study (i.e., deadlines, meetings, etc.), yet is able to maintain balance in other aspects of their life (i.e., home, family, friends)." As a response, one participant commented that a thriving student is "someone who is able to perform all of the tasks they are required to do within their program," while also having "time for self-care (whether it be working out, napping, reading, cooking, etc.) and takes time to have a social life (not necessarily within the department only)."

Closely tied to the theme of connecting, participants also articulated that being able to maintain a healthy social life was a critical component of student thriving. Participants spoke of attending "social events" and being able to maintain a connection with friends and family beyond their programs of study. Furthermore, a thriving student was viewed by participants as someone who is "able to cope" with the stressors of the program and the challenge of balancing multiple demands. For example, one survey response suggested: "If they are facing adverse situations, for example mental health challenges, they are coping with them and have strategies in place to allow them to maintain their well-being." One participant summed up the ideas of many by stating: "A thriving student is one who goes through the ups and downs of well-being, but understands how to cope with and manage." Finally, balancing was also viewed by participants from a financial perspective, with many respondents articulating that a thriving student is not struggling financially. For instance, several participants highlighted that a thriving student likely is "financially stable," has "secured grants/fellowships," and, in some cases, have been "awarded scholarships."

Enjoying. The theme of enjoying suggests that a thriving graduate student displays positive emotions and possesses feelings of satisfaction within their program of study. Participants articulated that a thriving student is likely to feel content, express happiness, and enjoy the experience of graduate school. For example, one participant asserted that a thriving graduate student is "someone who is enjoying their courses and the interactions and relationships with their profs and classmates." Another participant commented: "A student who is thriving in my program is one I would describe as happy, engaged, and excited to be here." Moreover, a thriving graduate student was understood to possess interest, love, and passion for their area of study, research, and work. For example, numerous participants highlighted that thriving graduate students are "passionate about their work," research topics, areas of study, and about learning, in general. One survey response read: "They are interested in the program and love to learn more." Another suggested: "A student who is thriving is one who is excited about the work they are doing and motivated to do their research."

In addition to these feelings of happiness, enjoyment, and passion, participants asserted that a thriving graduate student is able to control the stress associated with their work. One participant asserted that a thriving student is "someone who 
doesn't sweat the small stuff and doesn't get hung up on little details," while another commented that such a student is "not overwhelmed with deadlines or stressed about it." This finding suggests that thriving not only involves the presence of positive emotions and dispositions, but also the absence of an abundance of negative stressors.

Being. The theme of being emerged from participants' descriptions that a thriving graduate student comes to and exists within their program of study with various personal resources, intentions, and desires. Participants described a thriving graduate student as someone who, among other things, is "hardworking," "knowledgeable," "creative," and "intelligent." Similarly, these students were also perceived as being "confident" in their abilities, skills, and potential, and as "someone who doesn't suffer excessive self-doubt." In addition, a thriving student was perceived as someone who is adaptable (e.g., "prepare [d] to handle unknowns in program, professional life, and personal life") and optimistic (e.g., "feeling hopeful about their future"), and as possessing clear goals and purpose (e.g., "grounded and plan for the future"). In this respect, the theme of being captures elements that reflect the inner workings, intrinsic traits, and self-motivation of students.

\section{Demographic and Quantitative Results}

Quantitative analysis of the 2,287 survey responses supported the finding that graduate students conceptualize thriving across a continuum, with $46.8 \%$ of participants articulating a primarily academic-focused conceptualization of thriving, $47.9 \%$ articulating a balanced academic and non-academic conceptualization of thriving, and $5.4 \%$ articulating a primarily non-academic-focused conceptualization of thriving.

There were statistical differences found by comparing the quantized conceptualizations of thriving by demographic factors using Pearson's Chi-Square goodness of fit tests.

Non-Differences: Time of Year and Year-to-Year. The proportions of thriving conceptualization responses were not different across any of the three years of the study (Chi-Sq = 2.714 , $\mathrm{df}=4, p=0.647$ ) or if the responses were taken in the spring or the fall of a given year $(\mathrm{Ch}-\mathrm{Sq}=2.818, \mathrm{df}=2$, $p=0.831$ ).

Difference 1: Gender. A majority of male students tended to hold academic conceptualizations as compared to their female peers who mostly held a balanced conceptualization (Chi-Sq = $63.55, \mathrm{df}=2, p<0.0001$ ). Students who identified as non-binary were few in number, precluding a balanced comparison, but reported similar conceptualizations as their female peers. Although there were many more female graduate students who responded to the survey, there was adequate male response to fully meet the assumptions for this statistical test.

Difference 2: Canadian and International Students. A higher proportion of international students tended to hold academic conceptualizations than domestic or out of province students who tended to hold balanced conceptualizations (Chi-Sq = $21.947, \mathrm{df}=4, p<0.0001)$. Although there were many more Canadian graduate students who responded to the survey, there was adequate international response to fully meet the assumptions for this statistical test.
Difference 3: Doctoral and Masters Students. A higher proportion of doctoral students tended to hold academic conceptualizations than their peers in masters' programs (Chi$\mathrm{Sq}=14.839, \mathrm{df}=3, p<0.0001)$. Doctoral students are less common than masters student reflecting the smaller, more exclusive, and specialized program, however there was adequate doctoral student response to fully meet the assumptions for this statistical test.

Difference 4: Masters Thesis and Project Students. A higher proportion of masters thesis students tended to hold academic conceptualizations than their peers completing masters projects programs $($ Chi-Sq $=9.677, \mathrm{df}=2, p<0.002$ ).

Difference 5: Graduate Student Field of Study. A Chi-Square test $(\mathrm{Chi}-\mathrm{Sq}=221.532, \mathrm{df}=80, p<0.0001)$ revealed that there were differences in conceptualization between graduate departments or fields of study. Whereas science-based (e.g., biology, physics) and humanities-based (e.g., English, History) programs universally held more academic conceptualizations, only a few fields of study held majority balanced conceptualizations, namely: psychology, rehabilitation therapy, religious studies, nurse practitioner, health quality improvement, and geography and urban planning programs.

\section{DISCUSSION}

The purpose of this research was to examine how graduate students describe and understand student thriving within their post-secondary programs of study. To achieve this purpose, we sought the perspectives of graduate students to develop a contextually appropriate conceptualization of graduate student thriving. Findings from this study provide a foundational understanding of how student thriving can be conceptualized as a holistic, interconnected, and multi-dimensional construct within the context of graduate studies. Together, these findings provide unique insight into the experience of positive functioning that enables the subsequent development of a data-driven and contextually appropriate definition of thriving, whereby graduate student thriving is understood as an individual's holistic (social, emotional, physical, cognitive, [spiritual]) experience of optimal functioning within the context of their higher education program of study. This experience of positive functioning is strengthened by an individual's ability to achieve, engage, connect, balance, and enjoy at levels appropriate to their individual needs within the context of their graduate studies.

\section{Graduate Student Thriving: A Complex and Multi-Dimensional Construct}

Like other work focusing on thriving across the lifespan (e.g., Spreitzer et al., 2005; Nesbitt, 2019), this study underscores the idea that student thriving is inextricably grounded within the context of school, in this case graduate programs and institutions of higher education, and in connection to their lives beyond school. This finding was evident in the way that participants described graduate student thriving through the six overarching themes (achieving, engaging, connecting, balancing, enjoying, 
and being), and was further supported by the quantitative data indicating that the majority of participants conceptualized thriving as being primarily academic or a balance of academic and non-academic in focus. Very rarely did participants describe thriving as being completely disconnected from the academic realm, suggesting that graduate student thriving is intricately connected to graduate education and uniquely mediated by individual experiences within their programs of study.

It would appear that thriving within graduate education is driven by experiencing and maintaining a balance between continuity and discontinuity over time in pursuit of positive functioning. The idea that thriving was not a permanent state and, rather, an active process was prevalent within the data, highlighting the need for conscious effort to be made-on the part of both the institution and individual - to create and seek out supportive conditions whereby thriving can be achieved. The idea that the experience and extent to which someone is thriving can vary over time is well-supported in the literature. For example, Nesbitt (2019) found that both parents and educators of Kindergarten students described children's experiences of thriving as varying over the course of a school year. Similarly, Lerner et al. (2010) viewed thriving among adolescents as a process that involves growth and development over time. Likewise, Benson and Scales (2009) described thriving as a dynamic and bi-directional relationship observed over time between an adolescent and their developmental context. The current study showed these same effects reflected in the thematic and statistical analyses, and illustrate that these effects also occur at the graduate education level.

While there was variation in the way that graduate students described thriving, many commonalities among the conceptualizations were evident. The six overarching and interconnected themes of achieving, engaging, connecting, balancing, enjoying, and being highlight the complexity of student thriving and illustrate its multi-dimensional nature, a finding that adds strength to similar discoveries and observations in the area of positive psychology (Benson and Scales, 2009; Dodge et al., 2012). Each participant described thriving in unique and individualized ways, while also contributing to a rich understanding of what it means to thrive within the context of graduate studies. The fact that participants articulated diverse descriptions of thriving - with some conveying a purely academicfocus and others a more balanced approach-is evidence enough that a one-size-fits-all approach to supporting graduate students will not suffice. The finding that graduate students of various programs, degrees, and genders conceptualize thriving in different ways, alongside emerging evidence that thriving varies over time, illuminate the need for student support to be tailored to the meet the dynamic and individualized needs of students. Such an approach should not only address the various facets of thriving, but also recognize the stage at which students are currently engaged within their programs of study. For example, students at the beginning of a project-based masters program likely require a different type of support than doctoral students nearing completion of their program.

Of the six overarching themes, balancing was among the most well-supported, especially in reference to establishing and maintaining some form of work-life balance. This finding accentuates the importance of recognizing graduate students as existing within both the context of graduate school and the greater world beyond (Sprung and Rogers, 2020). In addition to achievement and engagement in an academic sense (e.g., Larivière, 2013), this study illustrates the ways that relationships, family, health, and financial responsibilities impact a student's ability to thrive (e.g., Rummell, 2015; Dericks et al., 2019; Ahn and Davis, 2020; Blanchard and Haccoun, 2020). These findings are important for anyone who works with graduate students in a professional sense as it highlights the need for success promotion (Schreiner, 2010) and for institutions of higher education to provide support that reach beyond solely academics. Furthermore, these findings may be insightful for graduate students as a guide to self-direct their thriving by building and maintaining networks of support both inside and outside the academic institution.

The theme of connecting illuminated the critical contribution that relationships and interpersonal interactions and supports make to student thriving. In particular, the qualitative findings cast light on the integral role that supervisors play in the graduate student experience (Blanchard and Haccoun, 2020). The finding that positive and supportive relationships are critical to thriving align with ideas presented by Schreiner (2013), Schreiner (2010), who asserts that experiencing a sense of community is a prevalent indicator of College student thriving and calls on institutions to foster a sense of community on campus. Similarly, Arghash (2018) examination of the experiences of four female graduate students found that students' sense of connectedness and mentorship were key factors affecting students' individualized ability to thrive. At a much younger age, Nesbitt (2019) exploration of thriving in the early years revealed that positive relationships with peers and educators were both an indicator and support for student thriving. Among the connections contributing to student thriving, the current study highlights the importance of a primary mentoring figure-in the case of graduate studies, the supervisor-as being among the most important drivers of thriving for a graduate student, as corroborated elsewhere in the literature (e.g., Wisker and Robinson, 2016; Makhamreh and Kutsyuruba, 2020). Participants shared both inspiring and heartbreaking stories illustrating the extent to which they were impacted by and dependent on (or at the mercy of) supervisors for their academic progress. In this study, the influence of a supervisor appeared to have a tremendous effect on the level of thriving experienced by a graduate student. Therefore, the ongoing development of skilled supervisors should be considered a priority for any graduate program aiming to support the thriving and well-being of their students.

Previous examinations of human thriving in various contexts highlight affective properties associated with thriving. For example, thriving has been defined as a psychological state in which an individual experiences a joint sense of vitality and learning (Spreitzer et al., 2005). Thriving has also been described as animated or powered by passion for and action to nurture selfdriven interests, skills, or capacities (Benson and Scales, 2009). In this study, positive dispositions and emotions were inextricably 
linked to student thriving, with participants expressing feelings such as happiness, enjoyment, passion, enthusiasm, and interest. While the data is not causal as to whether these traits directly powered thriving, the patterns showed that they were clear predictors of a thriving graduate student. It can, therefore, be argued that a focus on sustaining enjoyment and other engagement traits will likely facilitate better student outcomes and well-being. Students should be encouraged to follow passions and contribute to their programs of study in ways that fosters enthusiasm and brings intrinsic joy and happiness. Also, even with the ups and downs that come with progress through a graduate program (continuity and discontinuity), those working with graduate students should view persistent negative emotions and dispositions as an indicator that a student is likely in need of support.

\section{Individual and Contextual Factors at Play}

The quantitative findings section identifies differences within the sample that illustrate that some demographic factors impact the experience of thriving. The finding that graduate students, in the aggregate, conceptualized thriving differently by demographics, but not by time of year or year-to-year, points to the idea that thriving might be impacted by an individual's life history and past experiences and mediated by the culture, ethos, and pressures espoused by graduate programs and within institutions of higher education. The differences by gender revealed that male students, in the aggregate, tended to hold primarily academic conceptualizations, positioning academic prowess as their main consideration of thriving. This finding is compared to a more balanced conceptualization of positive functioning held by the majority of female students.

Doctoral students were far more likely to hold an academic conceptualization of graduate student thriving when compared to masters students who mostly held a balanced conceptualization. This finding may be unsurprising given that doctoral programs are more likely to be all-consuming and individuals who selfselect may be more academically inclined (Tamburri, 2013; Canadian Association for Graduate Studies, 2018). Relatedly, doctoral programs in Canada typically house more male than female students, which might in-part contribute to this finding (Canadian Association for Graduate Studies, 2018). Comparing masters programs, participants within thesis-based programs were more likely to hold academic views than those completing projects, who tended to hold more balanced conceptualizations. These findings hint that the process of completing a thesis or dissertation may dominate a student's perception of thriving, promoting an all-encompassing view if not actively mitigated by the prevailing academic culture of the department and/or institution.

The finding that how thriving was conceptualized differed among graduate departments points to varying cultural factors within graduate programs. For example, graduate healthprofessions programs, such as nurse practitioner, rehabilitation therapy, and medical residency programs, held balanced conceptualizations of graduate student thriving. A possible explanation for these balanced views could be the demanding nature of entry into these highly competitive programs, combined with an emerging understanding of burnout and performance- related stress emerging from literature extolling the importance of thriving beyond academics as a measure of success (e.g., Kennedy et al., 2019).

Much like Dodge et al. (2012) observation of the ill-defined nature of what well-being looks like in practice, the fact that participants described thriving in various ways and with differing focal points (academic vs. balanced perspective of thriving) highlights the complexity of seeking to understand the graduate student experience through a positive functioning lens. While some institutions may align with the perspective that the student experience should have a strict academic focus, finding from this study suggest that such a view will isolate a majority of graduate students and diminish their ability to thrive within their programs of study. This approach is problematic at an institutional level as thriving reminds us that the graduate student experience should be more than merely enduring or surviving. Leaders should also be wary of implementing superficial solutions and interventions that do not properly address or permeate systemic, programmatic, or individualized issues. This research points to some demographic and programmatic choices having real impact on how students conceptualize thriving and, by extension, success. Students internalize the priorities of their program in judging their value within higher education. Accordingly, we posit that the extolled values of graduate programs greatly impact student wellbeing and thriving and, thus, should be considered at all stages of program and policy development.

\section{Limitations}

This study has some limitations and delimitations. We noted slight skews in the sample, which included slightly more female representation in our sample than expected based on Canadian statistics. The survey sample also yielded more domestic students than international students and more masters than doctoral students, but this finding reflects the reality of graduate student demographics in Canada (Canadian Association for Graduate Studies, 2018). Our findings and conceptual model of thriving, therefore, approximate the reality of graduate student demographics with a slight saturation of female student input. We argue this does not damage the contribution, but rather is a product of female respondents being more likely to respond to a request for completing a survey. The research was conducted at one Canadian academic institution with many distinct departments who often act independently. Our focus on the perceptions and conceptualizations of graduate students was driven by self-report data, although it could be argued that this method was ideal for accessing the voices of a large number of key stakeholders. The quantitization procedure added an objective measure as all the responses were categorized with a rigorous procedure creating an additional layer of objectivity. Additionally, the thematic analyses were on the 2,287 responses to one openended question, where participants provided qualitative data ranging from bullet-point lists to short essays. Future studies could build on the foundation of this study to replicate and validate the findings at other institutions and examine if the dimensions of thriving are consistent among graduate students in other contexts. 


\section{Implications for Research and Practice}

Prior to this study, few researchers had attempted to address and understand student thriving at the post-secondary level (e.g., Schreiner et al., 2009), with the graduate student experience remaining largely untouched in the literature. This research is not only foundational in understanding how graduate students describe student thriving within their programs of study, but also provides a foundation upon which further research can be developed. Indeed, the six overarching themes-achieving, engaging, connecting, balancing, enjoying, and being-provide a beginning groundwork for understanding the graduate student experience, and how programs and institutions can best support those enrolled within their graduate programs. In addition to contributing a holistic, multi-dimensional, and contextually appropriate conceptualization of graduate student thriving, findings from this research illuminate several key ideas that are apparent in other understandings across the lifespan (e.g., Spreitzer et al., 2005; Benson and Scales, 2009; Schreiner, 2013; Nesbitt, 2019).

\section{Implications for Higher Education Leaders, Stakeholders, and Researchers}

Building on the foundation established through the current study and similar work on human thriving, future research can help to develop a more robust understanding of the factors that students associate with thriving within graduate programs and other higher education contexts, such as professional programs (e.g., law, industrial relations, teacher education). The current findings can serve as a tool for instrument development using the identified dimensions (six overarching themes) as the foundation for a thriving-focused survey. Likewise, qualitative research would enable researchers to further explore one or more of the six dimensions of thriving more deeply through the perspectives and voices of individual stakeholders. For example, interviews with graduate students might provide insight into the relationship between work-life balance and graduate student thriving and the challenges associated with establishing or maintaining such a balance. Moreover, the high percentage of women, domestic students, and master's students evident in our sample highlights the need for further research seeking the perspectives of specific graduate student groups. For example, exploring thriving among international master's and doctoral students or among student-parents.

Furthermore, the findings from this research call for the development and implementation of policy and interventions aimed at facilitating student thriving using the six overarching themes or dimensions as guidelines. These findings can also help to inform the development of thriving-promoting tools for practice, such as an inventory for supporting thriving within higher education (Soleas et al., 2019 in press). This study showed that different factors, such as the type of program and the cultural elements within a program matter when attending to student thriving. Considering these findings, efforts to address student wellness and burnout are necessary in programs as such endeavours may move students toward a balanced (and possibly healthier) conceptualization of thriving. This approach is in opposition to placing single-minded focus on the academic prowess of students, which may come at the cost to their overall well-being. It is plausible that students internalize the priorities of their program in judging their value, which feeds the reproduction of program culture year-over-year. A program that emphasizes productivity at any cost can subtly influence students to prioritize academic prowess at the natural cost of broader holistic health and wellness. Supporting students in their ability to thrive within graduate programs requires the recognition that students are more than their academic accomplishments (e.g., Schreiner, 2010). A program that emphasizes a balanced approach to thriving may, among other things, influence students to establish and maintain a healthy work-life balance without having a negative impact on broader holistic health and wellness (Sprung and Rogers, 2020).

\section{Implications for Current and Prospective Graduate Students and Members of Their Networks and Communities}

Findings from this study have several immediate implications for current and prospective graduate students, as well as members of their networks and communities. This study illustrates that thriving is a contextually-grounded, holistic, and individualized experience. Graduate students can use the six themes emerging from the current work as a foundation for reflection and identification of potential areas in need of support. In recognizing their own thriving needs in relation to their program of study, students may be better equipped to seek out and advocate for appropriate support. Findings from our study underscore the integral role that connections and relationships play in graduate student thriving. This finding serves as a call for current and prospective students to seek out and attend to positive and supportive relationships among their networks, such as peers, faculty, and supervisors. Attending to such connections may not only impact their individual ability to thrive within their program of study, but also foster an atmosphere of support among peers and collegial colleagues. Likewise, findings from this study highlighted how establishing and maintaining some form of work-life balance was integral to many graduate students' ability to thrive. Thus, it is recommended that current and future students consider how this type of balance might be established and maintained throughout the school year. Similarly, those who work closely with graduate students, such as supervisors or instructors, should also consider how they might support such an endeavour in practice (e.g., attention to scheduling and expectations).

The fact that participants identified work-life balance as an integral part of thriving indicated that while graduate student thriving is grounded within the context of graduate school, it is still connected to all aspects of a student's life. In this respect, there may be a bleeding effect in that life outside of school (e.g., birth of a child, medical diagnosis, death of a family member, global pandemic) can impact a student's ability to thrive within their program of study. As a result, graduate students should be armed with the knowledge that their lives outside their program will likely affect their thriving in the program with limitations on the potential to compartmentalize. Similarly, those working with 
graduate students should recognize that life beyond academic studies can have an impact on a student's ability to thrive within their program of study-not just life outside of school, but also life within the university (e.g., doctoral orphans; Wisker and Robinson, 2013). Once again, this idea echos the notion presented by Schreiner (2010) that thriving in higher education is about more than merely obtaining top grades.

\section{CONCLUSION}

Graduate programs foster the development of future researchers, scholars, professionals, and leaders. The scholastic habits formed within graduate programs are likely the habits that individuals will carry forward into their future jobs. If students are programmed to overwork and view their value as only their academic value, institutions of higher education are setting up a generation of scholars for unproductive competitiveness, burnout, less collegial collaboration, and less fulfilling lives. Graduate programs that are serious about helping students thrive will prioritize factors across the various dimensions of thriving to help students broadly and holistically improve their overall wellbeing. Moreover, drawing on the holistic, interconnected, and multi-dimensional nature of thriving, interventions should focus on enhancing the potential for students to maximize their achieving, engaging, connecting, balancing, enjoying, and being. In this study, graduate students shared what it means to thrive and have shed light on the factors that

\section{REFERENCES}

Acker, S., and Haque, E. (2017). Left Out in the Academic Field: Doctoral Graduates Deal with a Decade of Disappearing Jobs. Can. J. High. Educ. 47 (3), 101-119. doi:10.7202/1043240ar

Ahn, M. Y., and Davis, H. H. (2020). Students' Sense of Belonging and Their SocioEconomic Status in Higher Education: a Quantitative Approach. Teach. Higher Educ. 40, 1-14. doi:10.1080/13562517.2020.1778664

Al Makhamreh, M., and Kutsyuruba, B. (2020). Leadership Self-Efficacy (LSE) in Doctoral Programs: Examining the Supervisors' Lived Experiences in Canadian Universities. JOHEPAL 1 (2), 7-23. doi:10.29252/johepal.1.2.7

Alena, P., and Cliff, H. (2018). Balancing Graduate School and Mothering: Is There a Choice?. Int. J. Doctoral Stud. 13, 313-326. doi:10.28945/4109

Arghash, N. (2018). Thriving in Higher Education: Voices of Four Female Graduate Students. Kingston, ON, Canada: Queen's University. Available at: https://qspace. library.queensu.ca/bitstream/handle/1974/23988/Arghash_Nadia_S_201803_ MED.pdf? sequence=2\&isAllowed=y. (Accessed May 17, 2021).

Association of Universities and Colleges of Canada (2011). Trends in Higher Education. Enrolment 1, 1-70. doi:10.1126/science.29.750.759

Basit, T. N. (2010). Conducting Research in Educational Contexts. Continuum.

Benson, P. L., and C. Scales, P. (2009). The Definition and Preliminary Measurement of Thriving in Adolescence. J. Positive Psychol. 4 (1), 85-104. doi:10.1080/17439760802399240

Berea, A., Tsvetovat, M., Daun-Barnett, N., Greenwald, M., and Cox, E. (2015). A New Multi-Dimensional Conceptualization of Individual Achievement in College. Decis. Anal. 2 (1), 1-15. doi:10.1186/s40165-015-0012-8

Blanchard, C., and Haccoun, R. R. (2020). Investigating the Impact of Advisor Support on the Perceptions of Graduate Students. Teach. Higher Educ. 25 (8), 1010-1027. doi:10.1080/13562517.2019.1632825

Braun, V., and Clarke, V. (2019). Reflecting on Reflexive Thematic Analysis. Qual. Res. Sport Exerc. Health 11 (4), 589-597. doi:10.1080/2159676X.2019.1628806 impact their ability to do so within their programs of study. Now, it is our turn to listen and act.

\section{DATA AVAILABILITY STATEMENT}

The raw data supporting the conclusions of this article will be made available by the authors, without undue reservation.

\section{ETHICS STATEMENT}

The studies involving human participants were reviewed and approved by Queen's University General Research Ethics Board. The patients/participants provided their written informed consent to participate in this study.

\section{AUTHOR CONTRIBUTIONS}

All authors listed have made a substantial, direct, and intellectual contribution to the work and approved it for publication.

\section{FUNDING}

The authors gratefully acknowledge funding support from the Social Program Evaluation 558 Group at Queenâ $€^{\mathrm{TM}} \mathrm{s}$ University.

Breen, J. M. (2019). “Thriving in Higher Education: Creating the New Normal through Resilience," in Management and Administration of Higher Education Institutions at Times of Change (Emerald Studies in Higher Education, Innovation and Technology). Editors A. Visvizi, M. Lytras, and A. Sarirete (Emerald Publishing Limited), 85-98. doi:10.1108/978-1-78973-627420191013

Bundick, M. J., Yeager, D. S., King, P. E., and Damon, W. (2010). “Thriving across the Life Span," in The Handbook of Life-Span Development, London, UK: John Wiley \& Sons. doi:10.1002/9780470880166.hlsd001024

Canadian Association for Graduate Studies (2018). 44th Statistical Report, 2018: Part I Canadian Association for Graduate Studies. Available at: https://cags.ca/ wp-content/uploads/2019/04/44th-Statistical-Report-Part-1-2018.pdf. (Accessed May 17, 2021)

Canadian Association for Graduate Studies (2006). A Profile of Master's Degree Education in Canada Canadian Association for Graduate Studies. Available at: https://heinonline.org/HOL/License. (Accessed May 17, 2021).

Canadian Association for Graduate Studies [CAGS] (2012). Graduate Studies: A Practical Guide. Ottawa, Canada: Canadian Association for Graduate Studies. Available at: https://secureservercdn.net/45.40.150.136/bba.0c2.myftpupload. com/documents/publications/best_practices/Graduate_Studies_A_Practical_ Guide_FINAL_15OCT12.Eng.pdf. (Accessed May 17, 2021).

Charles, S. T., Karnaze, M. M., and Leslie, F. M. (2021). Positive Factors Related to Graduate Student Mental Health. J. Am. Coll. Health, 1-9. doi:10.1080/ 07448481.2020.1841207

Creswell, J. W., and Clark, V. L. P. (2017). Designing and Conducting Mixed Methods Research. 3rd ed. Thousand Oaks, CA: Sage.

Creswell, J. W., and Creswell, J. D. (2017). Research Design: Qualitative, Quantitative, and Mixed Methods Approaches. Thousand Oaks, CA: Sage publications.

Cullen, K. L., Gerbasi, A., and Chrobot-Mason, D. (2018). Thriving in Central Network Positions: The Role of Political Skill. J. Manage. 44 (2), 682-706. doi:10.1177/0149206315571154 
Declou, L. (2016). Who Stays and for How Long: Examining Attrition in Canadian Graduate Programs. Can. J. Higher Educ. 46 (4), 174-198. Available at: http:// journals.sfu.ca/cjhe/index.php/cjhe/article/view/185181/pdf.

Dericks, G., Thompson, E., Roberts, M., and Phua, F. (2019). Determinants of PhD Student Satisfaction: the Roles of Supervisor, Department, and Peer Qualities. Assess. Eval. Higher Educ. 44 (7), 1053-1068. doi:10.1080/02602938.2019.1570484

Dodge, R., Daly, A., Huyton, J., and Sanders, L. (2012). The challenge of Defining Wellbeing. Intnl. J. Wellbeing 2 (3), 222-235. doi:10.5502/ijw.v2i3.4

Evans, T. M., Bira, L., Gastelum, J. B., Weiss, L. T., and Vanderford, N. L. (2018). Evidence for a Mental Health Crisis in Graduate Education. Nat. Biotechnol. 36 (3), 282-284. doi:10.1038/nbt.4089

Giamos, D., Lee, A. Y. S., Suleiman, A., Stuart, H., and Chen, S.-P. (2017). Understanding Campus Culture and Student Coping Strategies for Mental Health Issues in Five Canadian Colleges and Universities. Can. J. High. Educ. 47 (3), 136-151. doi:10.7202/1043242ar10.47678/cihe.v47i3.187957

Grayson, J. L., and Alvarez, H. K. (2008). School Climate Factors Relating to Teacher Burnout: A Mediator Model. Teach. Teach. Educ. 24 (5), 1349-1363. doi:10.1016/j.tate.2007.06.005

Hoffman, S., Palladino, J. M., and Barnett, J. (2007). Compassion Fatigue as a Theoretical Framework to Help Understand Burnout Among Special Education Teachers. J. Ethnographic Qualitiative Res. 2 (1), 15-23. doi:10.1111/j.14678578.1975.tb01024.x

Hyun, J. K., Quinn, B. C., Madon, T., and Lustig, S. (2006). Graduate Student Mental Health: Needs Assessment and Utilization of Counseling Services. J. Coll. Student Develop. 47 (3), 247-266. doi:10.1353/csd.2006.0030

Jennings, P. A., and Greenberg, M. T. (2009). The Prosocial Classroom: Teacher Social and Emotional Competence in Relation to Student and Classroom Outcomes. Rev. Educ. Res. 79, 491-525. doi:10.3102/0034654308325693

Johnson, R. B., and Onwuegbuzie, A. J. (2004). Mixed Methods Research: A Research Paradigm Whose Time Has Come. Educ. Res. 33 (7), 14-26. doi:10.3102/0013189x033007014

Kennedy, M. C., Boyd, J., Mayer, S., Collins, A., Kerr, T., and McNeil, R. (2019). Peer Worker Involvement in Low-Threshold Supervised Consumption Facilities in the Context of an Overdose Epidemic in Vancouver, Canada. Soc. Sci. Med. 225, 60-68. Available at: http://10.0.3.248/j.socscimed.2019.02.014. doi:10.1016/ j.socscimed.2019.02.014

Koenig, A. (2014). Learning to Prevent Burning and Fatigue: Teacher Burnout and Compassion Fatigue. Electronic Thesis and Dissertation Repository. 1928. Available at: https://ir.lib.uwo.ca/etd/1928.

Larivière, V. (2013). PhD Students' Excellence Scholarships and Their Relationship with Research Productivity, Scientific Impact, and Degree Completion. Can. J. High. Educ. 43 (2), 27-41. Available at: http://prophet.library.ubc.ca/ojs/index. php/cjhe/article/view/2270. doi:10.47678/cjhe.v43i2.2270

Lerner, R. M., Boyd, M. J., and Du, D. (2010). Adolescent Development. Corsini Encyclopedia Psychol. 1-2. doi:10.1002/9780470479216.corpsy0019

Lorusso, J. R., Johnson, A. M., Morrison, H. J., Stoddart, A. L., Borduas, C., Cameron, N., et al. (2020). Graduate Student Experience in Focus: a Photovoice Investigation of Physical and Health Education Graduate Students in Canada. Phys. Educ. Sport Pedagogy 25, 643-665. doi:10.1080/ 17408989.2020 .1789572

McAlpine, L., and Austin, N. (2019). Humanities PhD Graduates: Desperately Seeking Careers?. Can. J. High. Educ. 48 (2), 1-19. doi:10.7202/1057100ar

Mertens, D. M. (2014). Research and Evaluation in Education and Psychology: Integrating Diversity with Quantitative, Qualitative, and Mixed Methods. Thousand Oaks, CA: Sage.

Nesbitt, H. (2019). Understanding and Supporting Student Thriving in the Ontario Kindergarten Classroom. Kingston, ON: Queen's University.

Okahana, H., and Zhou, E. (2017). Graduate Enrollment and Degrees: 2006 to 2016. Available at: http://cgsnet.org/ckfinder/userfiles/files/CGS_GED16_ Report_Final.pdf. (Accessed May 17, 2021).

Owens, A., Brien, D. L., Ellison, E., and Batty, C. (2020). Student Reflections on Doctoral Learning: Challenges and Breakthroughs. Sgpe 11 (1), 107-122. doi:10.1108/SGPE-04-2019-0048

Pascale, A. B. (2018). "Co-Existing Lives": Understanding and Facilitating Graduate Student Sense of Belonging. J. Student Aff. Res. Pract. 55 (4), 399-411. doi:10.1080/19496591.2018.1474758
Patton, M. Q. (2015). Qualitative Research \& Evaluation Methods. 4th ed. Thousand Oaks, CA: SAGE Publications, inc.

Peters, R. L. (1997). Getting what You Came for: The Smart Student's Guide to Earning a Master's or a Ph. D. New York: Farrar, Straus and Giroux.

Posselt, J. (2021). Discrimination, Competitiveness, and Support in US Graduate Student Mental Health. Sgpe, 1-8. doi:10.1108/SGPE-07-2020-0042

Reed, M. J., and Kennett, D. J. (2017). The Importance of University Students' Perceived Ability to Balance Multiple Roles: A Comparison of Students with and without Disabilities. Can. J. High. Educ. 47 (2), 71-86. doi:10.47678/ cjhe.v47i2.187965

Rummell, C. M. (2015). An Exploratory Study of Psychology Graduate Student Workload, Health, and Program Satisfaction. Prof. Psychol. Res. Pract. 46 (6), 391-399. doi:10.1037/pro0000056

Saliba, R., and Slater, G. (2012). PhD Program Structures in Canada December 2012. Canadian Association for Graduate Studies. 1-9, 2012. Available at: http://www.cags. $\mathrm{ca} /$ documents/publications/best_practices/10_12_12_PhD_Program_ Structures_in_Canada_Report_R_Saliba.pdf.

Sandelowski, M., and Barroso, J. (2003). Classifying the Findings in Qualitative Studies. Qual. Health Res. 13 (7), 905-923. doi:10.1177/1049732303253488

Sandelowski, M., Voils, C. I., and Knafl, G. (2009). On Quantitizing. J. Mix Methods Res. 3 (3), 208-222. doi:10.1177/1558689809334210

Schreiner, L. A. (2010). The "Thriving Quotient". About Campus 15 (2), 2-10. doi:10.1002/abc.20016

Schreiner, L. A. (2013). Thriving in College. New Dir. Student Serv. 2013 (143), 41-52. doi:10.1002/ss.20059

Soleas, E. K., Coe-Nesbitt, H., Arghash, N. S., and Moucessian, A. M. (2019). Conceptualizing Thriving in Graduate School. AERA.

Spreitzer, G., Sutcliffe, K., Dutton, J., and Sonenshein, S. (2005). A Socially Embedded Model of Thriving at Work. Organ. Sci. 16 (5), 537-549. doi:10.1287/orsc. 1050.0153

Sprung, J. M., and Rogers, A. (2020). Work-life Balance as a Predictor of College Student Anxiety and Depression. J. Am. Coll. Health, 1-8. Available at: https:// doi-org.proxy.queensu.ca/10.1080/07448481.2019.1706540. doi:10.1080/ 07448481.2019.1706540

Tamburri, R. (2013). The PhD Is in Need of Revision. University Affairs. Available at: http://www.universityaffairs.ca/the-phd-is-in-need-of-revision. aspx (Accessed May 17, 2021).

Universities Canada (2020). 2019 Full-Time and Part-Time Fall Enrolment at Canadian Universities. Ottawa, Canada: Enrolment by University. Available at: https://www.univcan.ca/universities/facts-and-stats/enrolment-by-university/ (Accessed May 17, 2021).

Weiss, J. A., and Burnham Riosa, P. (2015). Thriving in Youth with Autism Spectrum Disorder and Intellectual Disability. J. Autism Develop. Disord. 45 (8), 2474-2486. doi:10.1007/s10803-015-2412-y

Wisker, G., and Robinson, G. (2013). Doctoral 'orphans': Nurturing and Supporting the success of Postgraduates Who Have Lost Their Supervisors. Higher Educ. Res. Develop. 32 (2), 300-313. doi:10.1080/ 07294360.2012 .657160

Wisker, G., and Robinson, G. (2016). Supervisor Wellbeing and Identity: Challenges and Strategies. Int. J. Res. Develop. 7 (2), 123-140. doi:10.1108/ ijrd-03-2016-0000610.1108/ijrd-03-2016-0006

Yusuf, J.-E. W., Saitgalina, M., and Chapman, D. W. (2020). Work-life Balance and Well-Being of Graduate Students. J. Public Aff. Educ. 26 (4), 458-483. doi:10.1080/15236803.2020.1771990

Conflict of Interest: The authors declare that the research was conducted in the absence of any commercial or financial relationships that could be construed as a potential conflict of interest.

Copyright $(02021$ Coe-Nesbitt, Soleas, Moucessian, Arghash and Kutsyuruba. This is an open-access article distributed under the terms of the Creative Commons Attribution License (CC BY). The use, distribution or reproduction in other forums is permitted, provided the original author(s) and the copyright owner(s) are credited and that the original publication in this journal is cited, in accordance with accepted academic practice. No use, distribution or reproduction is permitted which does not comply with these terms. 